\title{
Introduction: The Interplay of Embodiment, Enaction, and Culture
}

\author{
Christian Tewes, Christoph Durt, and Thomas Fuchs
}

While traditional theories of cognition tend to conceive of mental capacities as disembodied or merely supervenient on brain states, in recent decades the insight has spread that mental processes cannot be confined to activities inside the skull alone. The paradigm of enactive embodiment endeavors to overcome the limitations of traditional cognitive science by reconceiving the cognizer as an embodied being and cognition as enactive. According to a well-known early definition, cognition depends on "the kinds of experience that come from having a body with various sensorimotor capacities" (Varela, Thompson, and Rosch 1991, 173).

It is important not to overlook the other part of the definition of "embodied" in the enactive sense, namely, that "these individual sensorimotor capacities are themselves embedded in a more encompassing biological, psychological, and cultural context" (ibid.). Since Varela, Thompson, and Rosch's The Embodied Mind, a great number of books on biological and psychological aspects of embodiment have been published. The cultural context of enactive embodiment, by contrast, has not yet been explored in an interdisciplinary volume dedicated to this purpose. The present book does exactly this and thereby offers a starting point for more extensive studies of the cultural context of embodiment. It is a multidisciplinary investigation into the role of culture for embodied and enactive accounts of cognition, encompassing fundamental philosophical considerations, as well as the newest developments in the field.

Here we have brought together philosophical, neurophysiological, psychological, psychiatric, sociological, anthropological, and evolutionary studies of the interplay of embodiment, enaction, and culture. The constitution of the shared world is understood in terms of participatory and broader collective sense-making processes manifested in dynamic forms of intercorporeality, collective body memory, artifacts, affordances, scaffolding, use of symbols, and so on. The contributors investigate how preconscious and conscious accomplishments work together in empathy, interaffectivity, identifications of oneself with others through emotions such as shame, we-intentionality, and hermeneutical understanding of the thoughts of others. The shared world is seen as something constituted by intersubjective 
understanding that discloses things in the shared significance they have for the members of a culture. Special emphasis is put on phenomenological approaches to cognition and culture and their relation to other approaches.

Our introduction explicates the key concepts, relates them to relevant empirical research, raises guiding questions, and explains the structure of the book. Starting with a phenomenological approach to the intertwinement of mind, body, and the cultural world, we continue with an exploration of the concepts of intercorporeality and interaffectivity. The ideas underlying these concepts are put in dialogue with central tenets of enactivism. We then consider further cultural conditions, such as those of cognitive scaffolding, and explain how these cultural conditions in turn depend on the embodied interaction of human beings. Finally, we outline the book's structure and introduce the individual chapters.

\section{The Intertwinement of Body, Mind, and Cultural World}

The concept of enaction is generally meant to capture the active sensorimotor engagement of the organism with its environment by which the organism makes sense of the environment and potentially changes it. For humans, sense-making is largely a collective activity through which their environment becomes a world of shared significance. Humans collectively constitute the world not by creating it in a constructivist sense but by disclosing its intersubjective significance. Cultural forms of constitution include communication as well as collaborative interactions with others; these also shape and change the environment according to the needs of the group or community. Over time, the shared ways of sense-making and interaction are established as rituals, codes, or institutions and as such may be transmitted to subsequent generations. This cultural context impregnates and structures all conscious experience, as Merleau-Ponty explains with his notion of the "intentional arc":

The life of consciousness-cognitive life, the life of desire or perceptual life-is subtended by an "intentional arc" which projects round about us our past, our future, our human setting, our physical, ideological and moral situation, or rather which results in our being situated in all these respects. It is this intentional arc which brings about the unity of the senses, of intelligence, of sensibility and motility. (Merleau-Ponty [1945] 2005, 157)

Anticipating current enactive accounts, Merleau-Ponty regards conscious life as marked by an inherent connection between desire, cognition, perception, and motor agency, which he refers to with the Husserlian expression "I can" (Merleau-Ponty [1945] 2005, 159). These activities of consciousness are united through the intentional arc, which situates the conscious being through the medium of the lived body in the cultural world it inhabits. The arc encompasses one's individual situation, shared habits, and cultural forms of interaction, as well as more reflective cultural accomplishments such as ideology and morals. How deeply these impregnate consciousness can be seen in psychopathological disturbances, such as the disability of the patient Schneider to integrate the different modes of consciousness, which Merleau-Ponty traces back to disturbances of the intentional arc (156-157). 
The intentional arc conditions, for instance, the everyday perception of a chair or pencil in connection with possible motor actions, which today are called affordances (Gibson 1979; Thompson 2005). The significance of the chair and pencil is disclosed not in a further intentional act separated from the perceptual act but in the perception itself. Husserl (1966) distinguishes here between "passive" and "active" synthesis, which together constitute the intentional objects in the significance in which they are experienced. Conscious perception focuses on certain aspects but is always accompanied by a "horizon" of possibilities that is only "dimly conscious" (Husserl [1913] 1976, §27; see also Moran, this vol.). In the same vein, for Merleau-Ponty, the intentional arc is not just a spotlight on given objects but "makes them exist in a more intimate sense, for us" (Merleau-Ponty [1945] 2005, 157).

Proponents of the "enactive sensorimotor approach" explain the emergence of perceptual patterns as the result of the (en)active exploration and know-how of the agent and specific contingencies of sensory modalities that give rise to sense-specific patterns in perception (cf. O’Regan and Noë 2001). The perceptual pattern or gestalt, however, cannot be separated from its cultural meaning. The intentional arc thus encompasses cultural sense-making processes that are already in play at the prereflective level of motor intentionality, such as learning how to hold a spoon or to climb stairs. This indicates that the "sensorimotor unity of perception and action" needs to be understood in the context of culture.

Cultural sense-making processes build on social interactions that also provide the pragmatic context through which language gains its meaning and significance. The results of sense-making in turn add further layers of significance to the shared world that are expressed in cultural patterns of perceiving, thinking, beliefs, or ideology (cf. Durt, this vol.). Such shared forms of perception and thought are then reflected on in cultural ways, for example, in art and literature. Culture thus permeates sense-making processes from prereflective motor-perceptive levels to the highest forms of significance. The products of culture, such as artifacts, technology, and institutions, in turn become an integral part of sense-making processes.

Culture is constantly changing, and though one can speak of cultural evolution, it is not a unilinear process; it involves contradictory tendencies and competing subcultures. Culture is inherited nongenetically, not merely as "memes," which Richard Dawkins models on genetic inheritance ([1976] 2006, 189-201), but by means of ever new forms of appropriation, which make new sense of the cultural inheritance. Thus the study of the cultural context of cognition needs to go beyond simplistic concepts of culture and instead proceed in differentiated and interdisciplinary ways. It should not surprise us when this approach reveals unexpected connections between culture and embodied cognition.

While culture cannot be reduced to the material products of culture, such as tools or artifacts, these material products are important for sense-making processes themselves. The concept of "material culture" brings to the fore the "meaning-instantiating function" that embeds material things in the culturally shared world (Malafouris 2013, 97). Material things are part of the entire cognitive life because sense-making processes also include relations 
between human beings and artifacts that are in turn embedded in a wider network of material engagement (Malafouris and Renfrew 2010, 4). The meaning-instantiating character of tools is furthermore asserted by the "manipulation thesis," which claims that tools such as pencils, computers, and sentences allow the manipulation of cognitive accomplishments when rooted in the appropriate action-perception cycles. This allows for cognitive operations that could not be achieved without the help of such "cognitive prostheses" (Menary 2007, 83-85; 2010b, 240).

As an example of how deeply the manipulation processes are entrenched in sociocultural practices, consider the creation and institutionalization of an external storage system such as a library. The use and further development of such a collective memory system requires experts to develop norms on how to store and retrieve information effectively. At least some of these norms need to be passed on to other users and institutions, for instance, via institutionalized storage systems, which in turn have a huge impact on individual memory capacities. Especially those who can read and write are part of a system that considerably enhances the cognitive spatiotemporal boundaries of oral communication practices (Donald 1991, 311).

So far, our outline of the intertwinement of body, mind, and the cultural world has focused on the constitutional function of cultural practices. But how are these realized at the bodily level in the first place; in what way are they embodied? This question leads us to the foundational role of the intercorporeal and interaffective dimensions of human experience and cognitive development, which will be the topic of the next section. Section 3 then explains the contribution of dynamical systems theory and of the concept of participatory sensemaking to intercorporeality, and section 4 considers how embodied interactions are constantly shaped by the shared world in which they are embedded.

\section{Intercorporeality and Interaffectivity}

Merleau-Ponty's reference to the "human setting" in specifying constitutional elements of the intentional arc indicates that the actual encounter with other human beings, between the $I$ and the You, plays a foundational role for the enculturation of human beings. Dan Zahavi (2014) has argued that every conscious state has the character of mineness, thereby establishing an inseparable "minimal self" at the prereflective level of awareness. This book casts light from different angles upon the pivotal question of how intersubjective relations are related to that basic sense of self-awareness. Is the minimal self the constitutional base for the We in joint attention and collective intentionality (cf. Brinck, Reddy, and Zahavi, this vol.)? Or do intersubjective interactions play a foundational role for selfhood at every level of experience (cf. Ratcliffe, this vol.; Ciaunica and Fotopoulou, this vol.)? Or does this claim overlook a "thinner" and "thinnest" concept of the minimal self (cf. Zahavi, this vol.)?

A good starting point for explicating intersubjective relationships is the phenomenological notion of the "extended body," which is formed by means of mutual interactions 
between expressive and feeling bodies (Froese and Fuchs 2012, 211). The idea is not that other feeling bodies play the role of an extended cognitive device, such as Otto's notebook in the famous thought experiment that Clark and Chalmers (1998) use to illustrate the extended mind hypothesis. The point is rather that a new dynamical whole emerges through bodily interactions and interbodily resonance. Contrary to older strands of emotional theory in the cognitive sciences, affective states and processes are conceived not simply as "cognitive, or mental phenomena" (Colombetti and Thompson 2008, 51) but rather as affective qualities that manifest themselves in the atmosphere of interpersonal encounters (Fuchs 2013, 222-223). This creates an ongoing interaffective space, in which the body functions as a medium for emotional and affective states and processes. Emotions such as despair, shame, guilt, hate, and love are intentionally directed toward other persons but are also simultaneously expressed by internal bodily reactions (such as increasing heartbeat rates or specific neural activation patterns) and body postures, gestures, and facial expressions that are directly perceivable in social interactions and lead to interbodily resonance (Froese and Fuchs 2012, 212-213).

Besides emotions that have an intentional direction, there are also existential feelings that prestructure the entire experience of being-in-the-world. An example of an existential feeling is given by Matthew Ratcliffe, who explains:

The world as a whole can sometimes appear unfamiliar, unreal, distant or close. It can be something that one feels apart from or at one with. One can feel in control of one's overall situation or overwhelmed by it. One can feel like a participant in the world or like a detached, estranged observer staring at objects that do not feel quite "there." (Ratcliffe 2008, 37)

Existential feelings are of fundamental importance for the entire constitution of the social realm. They frame the background of our current affective states and also include feelings that concern social settings such as feeling generally respected or unwelcomed, confident or distrustful, and so on (Stephan 2012, 158). They modulate how we perceive and experience social encounters in the first place. The notion of existential feelings further elucidates the inseparability of cognitive processes and emotions and their intra- and interbodily interrelations. Contrary to the classical appraisal theory, cognitive evaluations do not precede or simply trigger the occurrence of emotional episodes (Lewis 2000, 41-42). Rather, cognitive and evaluative processes are always embedded in basic states of mood and episodes of bodily affection.

Some theorists think that empirical findings from studies of fast emotional reactions to not yet fully recognized perceptual patterns imply that emotional reactions and processes are disconnected from cognitive evaluation (Zajonc 1984, 121). They assume a reversed temporal order of emotional and cognitive processes. The term "affective appraisal" refers in this context to organismic reactions to situations that require a quick and automatic evaluation of whether they are a threat or an attack (Robinson [2005] 2007, 42). According to this view, the cognitive evaluation of the perceptual pattern (and early elicited emotional response 
toward it) occurs only at a later stage of processing. This view seems to be supported by neurophysiological work by LeDoux, who found that different pathways exist for processing, for example, dangerous stimuli. On the one hand, there is the "high road" whereby stimuli reach the amygdala by a route going from the thalamus to the cortex. The functional interpretation of this pathway is that the cortex assesses the afferent information to prevent inappropriate responses (LeDoux [1998] 1999, 163-165). On the other hand, there is the "low road" that stimuli take from the thalamus directly to the amygdala, bypassing the cortex (165).

As Thompson points out, however, the organism must anticipate future states and satisfy its present desires to stay alive and adapt to the environment, thereby creating its "own temporal life cycle" (Thompson 2007, 155; cf. Jonas 1966, 86). Affective appraisal is already the beginning of an active encounter with the environment. The adaptive and projective capacities of sense-making processes suggest that emotions and appraisals are strongly interdependent and interconnected. At every temporal stage of pattern formation, self-organizing emotional appraisal processes emerge. These can either acquire a quite stable formation during lifetime, such as in the case of existential feelings, or change very rapidly, such as in the case of atmospheric feelings (Colombetti and Thompson 2008, 58; Stephan 2012, 158).

The emotional space of atmospheric and existential background feelings furthermore prestructures, shapes, and expresses our interactions with others. Empirical research in developmental psychology documents the importance of interaffective attunement or shared emotions between infants and caregivers. From the second month of life, infants and adults share emotions and attune to each other by means of different behavior patterns in "protoconversations" (Stern 1985, 217; Trevarthen 1989). These are dyadic forms of social interaction, in which caregivers and infants touch, smile, move, or gaze in an affectionate, rhythmic, and turn-taking manner (Trevarthen and Aitken 2001; Tomasello et al. 2005, 681). An example is the rhythmically coupled hand movement of an infant during the speech of an adult (Trevarthen and Aitken 2001, 4).

Such emotions, moods, affections, and feelings do not only concern early forms of development. Intentional understanding, sharing goals, and developing plans together are still embedded in an affective and emotional space. The interaffective exchanges and attunements are essential for the socio-emotional learning processes. Sharing emotions and related evaluations guide children in using cultural artifacts and in acquiring regulative norms, values, and intentions in social life (Trevarthen and Aitken 2001, 16-17).

The relationship between emotional appraisal and evaluation of artifacts has been studied intensively with regard to social referencing. Infants use the adult's emotional appraisal of an event or object as a clue to regulate their own behavior toward such objects. For instance, infants are less inclined to play with a toy when mothers show disgust toward it (Hornik, Risenhoover, and Gunnar 1987, 943). Furthermore, emotions become themselves more and more refined due to their embeddedness in the process of enculturation (Carroll 1996, 268): they are associated with specific "paradigm scenarios" (association of objects, emotion types, 
and normal response reactions) and are further elaborated by storytelling, literature, art, film, and so on (De Sousa 1987, 182).

\section{Dynamical Systems Theory and Participatory Sense-Making}

The foregoing considerations on the interaffective dimensions of embodiment and the development of socioemotional appraisals challenge the assumption that those processes are appropriately described as linear causal sequences. They are better conceived as reciprocal nonlinear causal loops that can be described by concepts drawn from dynamical systems theory, which is consequently a major ingredient of enactivism. The central assumption here is that embodied cognition is a temporal aspect of living and evolving agents (van Gelder 1998; Thompson 2007, 38). As already mentioned, dynamical systems theory no longer conceptualizes cognitive processes as computational linear input-output functions but now understands them as self-organizing wholes, emerging from many interacting nonlinear feedback processes (Kelso 1995). What distinguishes these causal loops, besides their reciprocal structure, is their multilevel relation characterized by top-down (global to local) and bottom-up (local to global) processes across different levels of explanation (Thompson and Varela 2001, 419-420). This allows the explanatory integration of different layers of descriptions such as psychic and neural processes by means of concepts and research tools from dynamics (Lewis 2005, 169).

In the literature on embodied and extended cognition, dynamical systems theory has been applied to intercorporeal relations under the concept of coupling. Brains, bodies, and the environment are understood as components of an emergent coupled system, the brainorganism-environment system (Menary 2007, 42; Clark [2008] 2011, 24). An important example of such an emergent whole is the aforementioned extended body, which is created and sustained by means of interbodily resonance dynamics. How to understand the coupling between an organism and its environment is a controversial question, and one may ask if it is a symmetrical or an asymmetrical relation (Menary 2010a, 3-4). Proponents of the extended mind hypothesis have favored the symmetrical interpretation. They point out that a continuous, simultaneous, and reciprocal causal influence exists between two systems (Clark [2008] 2011, 24; Menary 2010b, 233). Enactivists have challenged this view because an organism is a system that not only maintains its own stability within the framework of specific background conditions but also is capable of adjusting its activities according to its needs and the demands of its environment (Campbell 2009, 466).

At this level of complexity, the concepts of agency and autonomous system come into play. The idea is that, beyond the structural coupling between different systems, the coupling is conceived as a first-order loop that is modulated by means of a second-order loop. Di Paolo specifies the latter as a relational, normative, and asymmetric sense-making process (Di Paolo $2009,15)$. A dynamical system that is able to maintain its identity is conceived as an autonomous entity, "a thermodynamically open system with operational closure that actively 
generates and sustains its identity under precarious conditions" (Thompson and Stapleton 2009, 24).

Enactivism uses the concept of coordination to extend the notion of coupling to the social realm. The fruitfulness of applying this concept to intercorporeal interactions is already indicated by an example from Kelso. An adult and a child are walking side by side at a beach without being physically coupled; they are not holding hands and don't continuously touch each other, and they may not be coupled biologically (Kelso 1995, 98). A further level of coordination occurs when they are talking to each other or simply adjust their steps to walk alongside each other, a somewhat fleeting synchronization that nevertheless results in a mutual adjustment of intentional movements with regard to interpersonal dynamics (Dumas, Kelso, and Nadel 2014, 1-2). When connected in coupled actions, the interactors are still engaging in individual sense-making processes. But at the same time, a new autonomous system with new coherent social patterns of significance emerges, for example, in reciprocal speech, dance, or simply joint walking, a process that has been conceptualized as participatory sense-making (De Jaegher and Di Paolo 2007; Di Paolo, Rohde, and De Jaegher 2010, 71). This is so because both agents actively modulate but do not entirely control the new emerging system and its global and local features.

Forms of coupled interaction are shaped by culture: language and ways of speaking, styles of dancing, the comfort distance from others, norms of interaction, and even typical gaits differ from culture to culture. But is this the only way in which coupled interactions are dependent on culture? The notion of participatory sense-making singles out the activity of making sense, yet the results of sense-making may in turn have a top-down influence on the sense-making process itself. For instance, dance is a behavior that has significance for the dancers, and the significance it has codetermines the dance they choose and the way they dance it. An example involving explicit reflection is sense-making through reciprocal speaking, in which the significance produced in the conversation guides the further progress of the conversation. Whenever such a top-down influence exists, sense-making behavior and the significance that emerges through it are interdependent. The significance of meaningful behaviors such as dancing and speaking is cultural not only in that it is produced by cultural ways of interaction but also in that it is influenced by patterns of significance that are part of a culture, such as those expressed in worldviews, ideologies, morals, and norms. At least for humans, sense-making needs to be understood in the context of culturally shared significance (cf. Durt, this vol.).

\section{Cultural Inheritance and Embodiment}

Culture not only guides our interactions and our access to and interpretation of the world we live in but also changes its material composition. The coupling of an organism and its habitat is also one of transformation and production of its environmental setting. Generally speaking, organisms both adapt to their environments and adapt their environment to 
themselves. They construct their own ecological niche, which in turn affects the organism's behavior and development (Sterelny 2010, 470). The web building of spiders, for instance, induces new forms of protective behavior such as camouflage by means of web decorations that conceal the spiders from predators. Bees, ants, wasps, and other insects build nests "that often themselves become the source of selection for many nest heat regulatory, maintenance, and defense behaviour patterns" (Laland, Odling-Smee, and Feldman 2000, 133). In other words, the construction of such complexes frequently results in "downstream consequences": organisms that engage in such activities often reshape the ontogenetic environment and the selection conditions for later generations (Sterelny 2010, 470).

The last aspect has special significance for cultural niche construction. Human beings engage in collaborative activities that are frequently mediated, enabled, and structured by artifacts, social institutions, language, and externalized memory systems such as inscribed stone tablets, libraries, or finally electronic devices. This allows the facilitation of skills and knowledge by means of intra- and intergenerational transmission; culture provides humans with "a second nongenetic ... inheritance system" (Laland, Odling-Smee, and Feldman $2000,132)$. Once new forms of skills and knowledge have developed, they can spread rapidly and are established in a culture. The "cultural ratchet" ensures that jumps in cultural evolution are established by social transmission techniques that enable cumulative cultural evolution (Tomasello 1999, 5-6; Tomasello et al. 2005, 675). The process of internalization and incorporation of cultural skills and knowledge is facilitated by scaffolding, which integrates new information with extant knowledge (Williams, Huang, and Bargh 2009, 1257). The transmission of learning strategies enables learners to engage in complex tasks and explorations that would otherwise be beyond their cognitive scope and acquired abilities (Hmelo-Silver, Duncan, and Chinn 2007, 100).

Downstream niche construction is also constituted at the group level; the learning environment of children encompasses norms, traditions, and techniques that are not controlled or transmitted by the individual parents or teachers (Sterelny 2006, 154). This implies that participatory sense-making is nontrivially framed by the entire world shared by a culture. Conversely, social interactions and culture never lose their foundation in ongoing processes of intercorporeality and interaffectivity, from imitative learning in the early ontogenetic process of enculturation up to the complex forms of social behavior and joint enactments of symbolic cultures (Tomasello 1999, 81; Donald 1991, 199-200). Individual forms of habitus, shared intercorporeality, and cultural development are part of an interplay of bottom-up and top-down processes.

The production of tools, larger social institutions, and external memory systems is anchored in and stabilized by the "habitual body" (Casey 1984, 284), which incorporates different levels of constitution through its plasticity, in particular that of the human brain (Clark [2008] 2011, 68). The creation of larger collective memory systems, mediated by new external storage systems, is simultaneously based on the capacities of habitual body memories. The key concept of habitus can be traced back to Aristotle's use of hexis, which is frequently 
characterized as the socially acquired disposition of thinking, feeling, and acting within a group, including lifestyle, language, taste, and the specific posture of the body. Bourdieu famously describes the bodily basis of the habitus with his concept of "body hexis":

Body hexis speaks directly to the motor function, in the form of a pattern of postures that is both individual and systematic, because linked to a whole system of techniques involving the body and tools, and charged with a host of social meanings and values. (Bourdieu 1977, 87)

Through the acquired skills and enduring dispositions of intercorporeal interactions, cultural evolution is ingrained in the "second nature" of the human body, whose origin is sedimented and thus "forgotten as history" (Bourdieu 1990, 56). A new elaboration of habitual body memories can be found in Thomas Fuchs's concept of "collective body memories" (this vol.). The paradigm of enacted embodiment conceives of the human body not as a mere object but as the "existential ground for culture" (Csordas 1990, 5). The physical body is part of an embodied, living, and experiencing being that, together with other members of a culture, constitutes the shared world it lives in, can become aware of its significance, change it in meaningful ways, and is at the same time shaped by cultural significance.

The foregoing sections have depicted several lines of investigation that are becoming increasingly important for research on embodied and enactive cognition in the culturally constituted world. Each of the book's chapters elaborates further on the depicted lines of investigation. The results and insights the contributors present provide a basis for a better understanding of the interplay of embodiment, enaction, and culture.

\section{Contents of the Book}

Our anthology brings some of the most renowned scholars in the interdisciplinary study of embodied intersubjectivity together with the latest findings of up-and-coming researchers. Most of them-Ezequiel Di Paolo, Christoph Durt, John Elias, Shaun Gallagher, Vittorio Gallese, Thomas Fuchs, Katrin Heimann, Peter Henningsen, Dan Hutto, Hanne De Jaegher, Alba Montes Sánchez, Vasudevi Reddy, Zuzanna Rucińska, Glenda Satne, and Heribert Sattel-have collaborated for years in the interdisciplinary European research network Towards an Embodied Science of InterSubjectivity (TESIS). This book presents the final outcome of their cooperation in the TESIS network. Other authors contribute their expertise in key areas: Mark Bickhard, Ingar Brinck, Anna Ciaunica, Joerg Fingerhut, Aikaterini Fotopoulou, Duilio Garofoli, Laurence Kirmayer, Dermot Moran, Maxwell Ramstead, and Nicolas de Warren. Though the authors share phenomenological commitments, the underlying explanatory approach is interdisciplinary, bringing together fields such as philosophy, neuroscience, anthropology, psychology, and psychopathology.

The book is divided into four parts. Part 1, "Phenomenological and Enactive Accounts of the Constitution of Culture," explores the philosophical and conceptual foundations of the constitution of culture. The first three chapters explain groundbreaking work by 
Husserl, Merleau-Ponty, and Sartre, as well as philosophers from other traditions, such as Wittgenstein and Ryle. Building on these thinkers' ideas, the first two chapters explore the interconnections between embodiment, enaction, intercorporeality, meaning, significance, consciousness, and culture. The third chapter then relates this work to recent debates such as the one around participatory sense making, which in the fourth chapter is formulated anew by two of its best-known proponents. The last chapter of part 1 responds to several recent critiques of radical enactivism and deals with a key topic in embodied research today concerning the foundation of language and culture: how can we explain and understand the phylogenetic and ontogenetic origins of content with its specific properties of truth, reference, and inferential infrastructure within an enactive framework?

In the first chapter, Dermot Moran discusses the key connections in the work of Husserl and Merleau-Ponty between the phenomenological concepts of embodiment and intercorporeality and their role in the constitution of intersubjective sociality and, more generally, culture. From its origins at the outset of the twentieth century to the present day, phenomenology has led the way in exploring not only the first-person experience of lived embodiment (Leiblichkeit) but also the first-person and second-person plural experience of "intertwining" (Verflechtung, l'interlacs) and "intercorporeality" (intercorporéité), the latter being a concept that is found in a few scattered places in Merleau-Ponty's later writings but was first elaborated-although not by name-by Husserl and later Sartre. Moran examines how embodiment and intercorporeal intertwining are necessary steps in the constitution of culture.

In the chapter that follows, Nicolas de Warren explores the meaning and significance of Sartre's concept of "the third" within the social ontology of the Critique of Dialectical Reason. Through an examination of three different types of group formation (serial collectives, statutory groups, and sports teams), de Warren provides an analysis of central Sartrean insights into how individual action and collective agency are co-constituted. He also draws attention to the role ascribed to material objects, as well as ideological views and beliefs in the formation of social agency.

Christoph Durt offers a new view on the relation between consciousness and culture by investigating their intertwinement with significance. Against the widespread restriction of consciousness to phenomenal aspects and that of culture to "thick description," Durt argues that consciousness discloses aspects of significance, whereas culture encompasses shared significance, as well as the forms of behavior that enact significance. Significance is intersubjective and constantly reinstantiated in new contexts of relevance rather than belonging to single individuals (cf. Gallagher, this vol.), as well as embedded in the shared world to which we relate by cultural forms of thinking and sense-making. Bringing together insights on the role of consciousness for the constitution of the world from Husserlian phenomenology with those on cultural forms of behavior by Wittgenstein and Ryle, Durt distinguishes different levels of significance accomplished by embodied consciousness and interaction. He contends that the real issue underlying "hybrid" concepts of the mind consists not in embodied versus 
disembodied systems of production (cf. Di Paolo and De Jaegher, this vol.) but in different levels of significance accomplished by consciousness and culture. Consciousness is embodied on every level, and it integrates different levels of significance.

Ezequiel Di Paolo and Hanne De Jaegher summarize some of the main proposals of the enactive approach to social understanding and discuss some common misreadings of the notion of participatory sense-making. The emphasis on the role played by social interaction in the enactive perspective is, in their view, sometimes misinterpreted as entailing an interactionist stance, whereby individual processes are less relevant. They argue that this is not the case, and proceed to explain the central role played by individual agency, subpersonal processes, and subjective personal experience in the framework of participatory sense-making. Social interaction is defined as involving the co-arising of autonomous relational patterns, not under the full control of any participant, but without loss of individual autonomy for those engaged in the social encounter. Di Paolo and De Jaegher discuss how interactive patterns can sustain a deep entanglement between brain, body, and interactive dynamics during social engagement, as well as the functional role played in some cases by collective dynamics. They argue that hybrid approaches perpetuate dualistic distinctions between mind and body and contend that participatory sense-making, instead, offers precisely the dialectical tools for the self-deployment of the tensions that give rise to the individualist and interactionist frameworks.

Dan Hutto and Glenda Satne contend that radically enactive cognition (REC) does not imply that all forms of cognition are content involving and, especially, not root forms. According to radical enactivists, only minds that have mastered special kinds of sociocultural practice are capable of content-involving forms of cognition. The chapter addresses criticisms that have been leveled at REC's vision of how content-involving cognition may have come on the scene. In the first section, Hutto and Satne respond to the charge that REC faces a fatal dilemma when it comes to accounting for the origins of content in naturalistic termsa dilemma that arises from REC's own acknowledgment of the existence of the Hard Problem of Content. In subsequent sections, they address the charge that REC entails continuity skepticism, reviewing this charge in its scientific and philosophical formulations. Hutto and Satne conclude that REC is not at odds with evolutionary continuity, when both REC and evolutionary continuity are properly understood. Furthermore, although REC cannot completely close the imaginative gap that is required to answer the philosophical continuity skeptic, it is, in this respect, in no worse a position than its representationalist rivals and their naturalistic proposals about the origins of content.

Part 2, "Intersubjectivity, Selfhood, and Persons," focuses on the conceptual and empirical relationships of the self and enculturated full-fledged persons. If the most basic forms of the self are already embedded in intersubjectivity, one may think that there is no part of consciousness that is not impregnated with culture. But is there not something in the self that precedes all intersubjectivity? Dan Zahavi (2014) maintains that there is a "minimal self"; every consciousness experience has a character of mineness. Together with Brinck 
and Reddy (this vol.), he defends the claim that individual experience is not preceded by we-experience. In contrast, Matthew Ratcliffe as well as Anna Ciaunica and Aikaterini Fotopoulou argue in their chapters in different ways that even the "minimal self" needs to be conceived in intersubjective terms, a challenge taken up again by Zahavi in his subsequent response.

In the first chapter of part 2, Ingar Brinck, Vasudevi Reddy, and Dan Zahavi consider some arguments that could be adopted for the primacy of the we, and examine their conceptual and empirical implications. The question of the relation between the collective and the individual has had a long but patchy history within both philosophy and psychology. They argue that the we needs to be seen as a developing and dynamic identity, not as something that exists fully fledged from the start. The concept of we thus needs more nuanced and differentiated treatment than currently exists, distinguishing it from the idea of a "common ground" and discerning multiple senses of "we-ness." At an empirical level, beginning from the shared history of human evolution and prenatal existence, a simple sense of prereflective we-ness, the authors argue, emerges from second-person $I$-you engagement in earliest infancy. Developmentally, experientially, and conceptually, engagement remains fundamental to the we throughout its many forms, characterized by reciprocal interaction and conditioned by the normative aspects of mutual addressing.

Matthew Ratcliffe addresses the view that schizophrenia involves disturbance of the minimal self, and that this distinguishes it from other psychiatric conditions. He challenges the distinction between a minimal and an interpersonally constituted sense of self by considering the relationship between psychosis and interpersonally induced trauma. First, he suggests that even minimal self-experience must include a prereflective sense of what kind of intentional state one is in. Then he addresses the extent to which human experience and thought are interpersonally regulated. He proposes that traumatic events in childhood or in adulthood can erode a primitive form of "trust" in other people on which the integrity of intentionality depends, thus disrupting the phenomenological boundaries between intentional state types. Ratcliffe concludes that a distinction between minimal and interpersonal self is untenable, and schizophrenia should be thought of in relational terms rather than simply as a disorder of the individual.

This intersubjective constitution of the self is explored further in the next chapter, by Anna Ciaunica and Aikaterini Fotopoulou. They ask whether minimal selfhood is a built-in feature of our experiential life or a later, socioculturally determined acquisition, emerging in the process of social exchanges and mutual interactions. Building on empirical research on affective touch and interoception, Ciaunica and Fotopoulou argue in favor of reconceptualizing minimal selfhood so that it goes beyond such debates and their tacitly "detached," visuospatial models of selfhood and otherness. They trace the relational origins of the self back to fundamental principles and regularities of the human embodied condition, such as the amodal properties that govern the organization of sensorimotor signals into distinct perceptual experiences. Interactive experiences with effects "within" and "on" the physical 
boundaries of the body (e.g., skin-to-skin touch) are necessary for such organization in early infancy when the motor system is not yet developed. Therefore an experiencing subject is not primarily understood as facing another subject "there." The authors conclude that the minimal self is by necessity co-constituted by other bodies in physical contact and proximal interaction.

In the following chapter, Dan Zahavi responds to the critique of the concept of the minimal self by Ratcliffe and Ciaunica and Fotopoulou. Zahavi acknowledges that the discussion of the minimal self has entered a new phase with the foregoing chapters, not only because they engage with the recent arguments of Self and Other (Zahavi 2014) but also because their criticisms differ from the criticism offered in the past, for example, by advocates of a no-self view, narrativists, and phenomenal externalists. Rather than denying the existence of the minimal self, the critiques published here are concerned is with its proper characterization and interpersonal constitution. Zahavi maintains, however, that the minimal self is not interpersonally constituted. He argues that it can coherently be defined more thinly and independently of interpersonal aspects of the self, for which it is the condition of possibility.

Mark Bickhard presents a model of persons as emergent dynamic forms of sociocultural agency. Such a model requires a metaphysical framework that makes sense of the normative dynamic emergence of agents, which in turn requires a metaphysics of process. He also briefly addresses how this model of persons as interactive agents relates to persons as moral agents. Moreover, Bickhard turns against radical enactivism and holds that even organisms like frogs need normative truth-valued representational capacities, and that such capacities are incorrectly captured in the traditional encoding models of representation. He maintains that representational capacities are needed to understand the functional normative level of emergence of organisms in evolution and, a fortiori, persons in sociocultural settings. Decisive for the concept of persons, so Bickhard, is that they are individually constituted in interactive processes and potentialities as sociocultural agents.

Part 3, "Cultural Affordances and Social Understanding," explores the basis of social understanding, including the social understanding of significance in the context of its cultural conditions. The contributors here ask questions such as: What does it mean to feel ashamed of somebody else; how can we account for the social dimension of hetero-induced shame? What is the nature of affordance, how can we conceive of joint affordances, and how could they be produced by social interaction? What does it mean to pretend something? How can we understand cultural significance if most of the available evidence is limited to a few material items, such as scattered bones and traces of ornaments? How can the concept of radical enactive cognition (cf. Hutto and Satne, this vol.) be applied to evolutionary anthropology?

Shaun Gallagher argues in the first chapter that the distinction between significance and meaning made in debates about the nature of interpretation in hermeneutics is relevant to contemporary discussions of social cognition. He reviews the debates about interpretation, 
focusing on Gadamer's hermeneutics. Then, within the framework of a pluralist approach to social cognition, he discusses some problems with mind-reading approaches that attempt to get to the "inner" meaning of the other. He defends a Gadamerian view of social cognition that models our encounter with others on a dialogical interaction and the emergence of significance.

Within the literature, shame is generally described as a self-conscious emotion, meaning that shame is about the self that feels that emotion. But how can this account accommodate cases in which I feel ashamed of someone else? Alba Montes Sánchez and Alessandro Salice's chapter pursues two goals. The first is to vindicate the phenomenological credentials of what might be called "hetero-induced shame" and to resist possible attempts to reduce its specificity. The second goal is to show how the standard account of shame as self-directed can be made hospitable to cases of hetero-induced shame. They argue that a promising way to do this is by supplementing the standard account by a theory of group identification.

John Elias holds that in virtue of our sociability and plasticity we are especially open to altering and developing our capacities and abilities, thereby expanding the scope of available affordances. The distinctively dynamic and extensive nature of human abilities, however, raises questions concerning the ontology of affordances, given their relativity to abilities, their being relative to abilities. These questions are particularly pressing, since much of the power of the concept comes from the claim that affordances are real, that they exist in some sense. Resolving these issues, Elias suggests, involves taking the temporal dimension of abilities and affordances seriously, particularly in terms of interaction across multiple temporal scales. Such a temporal perspective encompasses the modulating role of motivation, as well as questions concerning the presence and salience of affordances. He ends by addressing abilities as they extend into, and are extended by, social interaction and coordination, and introduces the notion of joint affordances specifically, in contrast to the more general sociality of affordances.

Pretending is often conceptualized as an imaginative and symbolic capacity, explained in terms of mental representations. Zuzanna Rucińska proposes an alternative way to explain pretending by using affordances, instead of mental representations, as explanatory tools. Rucińska shows that a specific notion of affordance has to be appropriated for affordances to play the relevant explanatory roles in pretense. Her analysis opens up a discussion of the nature of affordances, clarifying how, in various conceptions, the environment and the animal play a role in shaping affordances. She then clarifies which notion best explains pretending, and suggests that a particular conception of affordances as dispositional properties of the environment (à la Turvey 1992) can make affordances explanatorily useful. Rucińska shows how environmental affordances together with animal effectivities, placed in the right context (formed by canonical affordances or other people), could form an explanation of basic kinds of pretend play. The idea is that some forms of cognitive activity, such as basic pretense, can be explained by embodied and enactive theorists without the need to posit mental 
representations. Social and cultural factors provide a crucial aspect of a coherent explanation of basic pretense.

Duilio Garofoli writes that evidence of feather extraction from scavenging birds by late Neanderthal populations, supposedly for ornamental reasons, has recently been used to bolster the case for Neanderthal symbolism and their cognitive equivalence with modern humans. This argument resonates with the idea that the production and long-term maintenance of body ornaments necessarily require a cluster of abilities defined here as the material symbolism package. This implies the construction of abstract meanings, which are then mentally imposed on artifacts and socially shared through full-blown mind reading, assisted by a metarepresentational language. However, a set of radical enactive abilities, above all direct social perception and situated concepts, suffices to explain the emergence of ornamental feathers without necessarily involving the material symbolism package. The embodied social structure created by body ornaments, augmented through behavioral-contextual narratives, suffices to explain even the long-term maintenance of this practice; no recourse to mentalism is needed. Costly neurocentric assumptions that conceive the material symbolism package as a homuncular adaptation are eschewed by applying a nonsymbolic interpretation of feathers as cognitive scaffolds. Garofoli concludes that the presence of body adornment traditions in the Neanderthal archaeological record does not warrant Neanderthals' cognitive equivalence with modern humans, for it does not constrain a metarepresentational level of meaning.

Part 4, "Embodiment and Its Cultural Significance," addresses the concept of the body in relation to culture. Here the contributors reevaluate the body in the light of studies in neurophysiology, cultural neurophenomenology, biopsychology, phenomenology, anthropology, and psychopathology. They argue that the human body is shaped by cultural forms of experiencing and conceptualizing. It is a carrier of collective memories, and its experience is an integral part of the world shared by the members of a culture. Furthermore, the body is malleable by cultural products such as movies and is dependent on culture.

Vittorio Gallese addresses the notion of embodiment from a neuroscientific perspective, by emphasizing the crucial role played by bodily relations and sociality in the evolution and development of distinctive features of human cognition. Gallese accounts for the neurophysiological level of description in terms of bodily formatted representations, and he replies to criticisms recently raised against this notion. The neuroscientific approach that Gallese proposes is critically framed and discussed against the background of the evo-devo focus on a rarely explored feature of human beings in relation to social cognition: their neotenic character. Neoteny refers to the slowed or delayed physiological and somatic development of an individual. Such development depends largely on the quantity and quality of interpersonal relationships the individual is able to establish with her or his adult peers. It is proposed that human neoteny further supports the crucial role played by embodiment, here spelled out by adopting the explanatory framework of embodied simulation, in allowing humans to engage in social relations and make sense of others' behaviors. This approach can fruitfully be used 
to shed new light on nonpropositional forms of communication and social understanding and on distinctive human forms of meaning making, such as the experience of artificial fictional worlds.

Thomas Fuchs holds that the concept of body memory comprises all forms of implicit memory that are mediated by the body and actualized without explicit intention in our everyday conduct-for example, habitual patterns of movement and perception, instrumental skills, or behavioral and cultural habits. The lifelong plasticity of body memory enables us to adapt to the natural and social environment, in particular to become entrenched and feel at home in the social and cultural environment. Fuchs introduces the concept of collective body memories that develop in social groups through recurrent shared experiences and lead to spatial and temporal patterns of joint group behavior. Examples of such memories are the formation of a well-attuned football team and its fluent interplay, the habitual ways of interacting that characterize a family, or the enactment of social ceremonies and rituals. In such situations, the intercorporeal memories of the individuals unite to form overarching procedural fields. Moreover, the interactive processes develop an autonomous or emergent dynamic involving the individuals in behavior they would not exhibit outside the formation. Once the group joins again in a similar configuration and situation, the resulting collective body memory is reactualized. Fuchs analyzes these phenomena mainly from a phenomenological, but also from a dynamical systems, perspective.

Joerg Fingerhut and Katrin Heimann explain that, over the last decade, the role of the spectator's body has become considerably more important in theoretical as well as experimental approaches to film perception. However, most positions focus on how cinema has adapted to the spectator's body over time, that is, on the basic principles of human perception and cognition, in developing its immersive power. This chapter presents the latest contributions to this topic while also providing a new stance regarding the relationship between the mind and movies. Drawing on selected research from embodied approaches to cognition and picture perception, the authors suggest that humans learn to see film by integrating filmic means into their body schemata and, through this process, develop a "filmic body," available to them during film watching and, possibly, also offscreen. Film language and film cognition are plastic products of mutual influence between films and embodied agents and thereby move the medium toward novel filmic means and us toward novel experiences. The authors propose a number of research designs for further exploring these claims.

Peter Henningsen and Heribert Sattel present and interpret data on significant cultural influences on pain-related psychosocial workplace conditions, one of the core issues of psychosomatic medicine, and discuss consequences for a cultural neuroscience of pain. Chronic pain encompasses the experience of the pain sensation itself and a whole universe of related emotions, thoughts, behaviors, and suffering; tissue damage is no necessary precondition for it. A biopsychosocial view of risk factors typically concentrates on the intra-individual level and includes genetic dispositions or injuries, for example, whereas an embodied approach emphasizing the "body being in the world" and integrating cultural perspectives seems more 
appropriate. However, recent epidemiological work has demonstrated the relevance of grouplevel psychosocial risk factors for chronic pain. Lack of social support at work, injustice, high levels of job stress, and effort-reward imbalance are important factors. Nevertheless, even these perspectives do not capture all relevant differences: studies in different societies reveal significant cultural influences, both in an "etic" and in an "emic" perspective. The link between culture and pain involves various factors. Culturally shaped ways of world making influence the interpretation, labeling, and treatment of distress. New knowledge on the relational biology of pain shows how culture determines differences in the neural processes underlying emotion and pain.

In the book's final chapter, Laurence Kirmayer and Maxwell Ramstead investigate the field of cultural psychiatry, which is concerned with understanding the implications of human cultural diversity for psychopathology, illness experience, and intervention. The emerging paradigms of embodiment and enactment in cognitive science provide ways to approach this diversity in terms of variations in bodily and intersubjective experience, narrative practices, and discursive formations. This chapter outlines an approach to cultural neurophenomenology and psychopathology through metaphor theory, which examines the interplay of culturally shaped developmental processes of embodied experience and narrative practices structured by ideologies of personhood and social positioning. The new paradigm has broad implications for psychiatric theory, research, and practice, and these are illustrated with examples from the cross-cultural study of delusions.

\section{Acknowledgments}

Christoph Durt's work on this book was supported by the DFG excellence initiative Cultural Dynamics in Globalised Worlds and by the European Union's Horizon 2020 research and innovation program under the Marie Skłodowska-Curie Individual Fellowship no. 701584.

\section{References}

Bourdieu, P. 1977. Outline of a Theory of Practice. Cambridge University Press.

Bourdieu, P. 1990. The Logic of Practice. Stanford University Press.

Campbell, R. 2009. A process-based model for an interactive ontology. Synthese 166:453-477.

Carroll, N. 1996. Theorizing the Moving Image. Cambridge University Press.

Casey, E. 1984. Habitual body and memory in Merleau-Ponty. Man and World 17:279-297.

Clark, A. [2008] 2011. Supersizing the Mind: Embodiment, Action, and Cognitive Extension. Oxford University Press.

Clark, A., and D. Chalmers. 1998. The extended mind. Analysis 65:1-11. 
Colombetti, G., and E. Thompson. 2008. The feeling body: Toward an enactive approach to emotion. In Developmental Perspectives on Embodiment and Consciousness, ed. W. F. Overton, U. Müller, and J. L. Newman, 45-68. Erlbaum.

Csordas, T. J. 1990. Embodiment as a paradigm for anthropology. Ethos 18 (1):5-47.

Dawkins, R. [1976] 2006. The Selfish Gene. Oxford University Press.

De Jaegher, H., and E. A. Di Paolo. 2007. Participatory sense-making: An enactive approach to social cognition. Phenomenology and the Cognitive Sciences 6:485-507.

De Sousa, R. 1987. The Rationality of the Emotions. Cambridge University Press.

Di Paolo, E. A. 2009. Extended life. Topoi 28:9-21.

Di Paolo, E. A., M. Rohde, and H. De Jaegher. 2010. Horizons for the enactive mind: Values, social interaction, and play. In Enaction: Toward a New Paradigm for Cognitive Science, ed. J. Stewart, O. Gapenne, and E. A. Di Paolo, 33-87. MIT Press.

Donald, M. 1991. Origins of the Modern Mind: Three Stages in the Evolution of Culture and Cognition. Harvard University Press.

Dumas, G., J. A. S. Kelso, and J. Nadel. 2014. Tackling the social cognition paradox through multi-scale approaches. Frontiers in Psychology 5:882. doi:10.3389/fpsyg.2014.00882.

Froese, T., and T. Fuchs. 2012. The extended body: A case study in the neurophenomenology of social interaction. Phenomenology and the Cognitive Sciences 11:205-236.

Fuchs, T. 2013. Depression, intercorporality, and interaffectivity. Journal of Consciousness Studies 20:219-238.

Gallagher, S. 2008. Direct perception in the intersubjective context. Consciousness and Cognition 17 (2): 535-543.

Gibson, J. J. 1979. The Ecological Approach to Visual Perception. Houghton Mifflin.

Hmelo-Silver, C. E., R. G. Duncan, and C. A. Chinn. 2007. Scaffolding and achievement in problembased and inquiry learning: A response to Kirschner, Sweller, and Clark (2006). Educational Psychologist 42 (2): 99-107.

Hornik, R., N. Risenhoover, and M. Gunnar. 1987. The effects of maternal positive, neutral, and negative affective communications on infant responses to new toys. Child Development 58 (4): 937-944.

Husserl, E. [1913] 1976. Ideen zu einer reinen Phänomenologie und phänomenologischen Psychologie: Allgemeine Einführung in die reine Phänomenologie (Text der 1-3 Auflage). Martinus Nijhoff.

Husserl, E. 1966. Analysen zur passiven Synthesis. Martinus Nijhoff.

Jonas, H. 1966. The Phenomenon of Life: Toward a Philosophical Biology. Harper \& Row.

Kelso, J. A. 1995. Dynamic Patterns: The Self-Organization of Brain and Behavior. MIT Press. 
Laland, K. N., J. Odling-Smee, and M. W. Feldman. 2000. Niche construction, biological evolution, and cultural change. Behavioral and Brain Sciences 23:131-175.

LeDoux, J. [1998] 1999. The Emotional Brain: The Mysterious Underpinnings of Emotional Life. Simon \& Schuster.

Lewis, M. D. 2000. Emotional self-organization at three time scales. In Emotion, Development, and SelfOrganization: Dynamic Systems Approaches to Emotional Development, ed. M. D. Lewis and I. Granic, 7-69. Cambridge University Press.

Lewis, M. D. 2005. Bridging emotion theory and neurobiology through dynamic systems modeling (target article). Behavioral and Brain Sciences 28:169-194.

Malafouris, L. 2013. How Things Shape the Mind: A Theory of Material Engagement. MIT Press.

Malafouris, L., and C. Renfrew. 2010. Introduction: The cognitive life of things; Archaeology, material engagement and the extended mind. In The Cognitive Life of Things: Recasting the Boundaries of the Mind, ed. L. Malafouris and C. Renfrew, 1-12. McDonald Institute Monographs.

Menary, R. 2007. Cognitive Integration: Mind and Cognition Unbound. Palgrave Macmillan.

Menary, R. 2010a. Introduction: The extended mind in focus. In The Extended Mind, ed. R. Menary, 1-25. MIT Press.

Menary, R. 2010b. Cognitive integration and the extended mind. In The Extended Mind, ed. R. Menary, 227-243. MIT Press.

Merleau-Ponty, M. [1945] 2005. The Phenomenology of Perception. Trans. C. Smith. Taylor and Francis e-Library.

O’Regan, J. K., and A. Noë. 2001. A sensorimotor account of vision and visual consciousness. Behavioral and Brain Sciences 24:939-1011.

Ratcliffe, M. 2008. Feelings of Being: Phenomenology, Psychiatry, and the Sense of Reality. Oxford University Press.

Robinson, J. [2005] 2007. Deeper Than Reason: Emotion and Its Role in Literature, Music, and Art. Clarendon Press.

Stephan, A. 2012. Emotions, existential feelings, and their regulation. Emotion Review 4 (2): 157-162. doi:10.1177/1754073911430138.

Stern, D. N. 1985. The Interpersonal World of the Infant: A View from Psychoanalysis and Developmental Psychology. Basic Books.

Sterelny, K. 2006. The evolution and evolvability of culture. Mind and Language 21 (2): 137-165.

Sterelny, K. 2010. Minds: Extended or scaffolded. Phenomenology and the Cognitive Sciences 9:465-481.

Thompson, E. 2005. Sensorimotor subjectivity and the enactive approach to experience. Phenomenology and the Cognitive Sciences 4 (4): 407-427. 
Thompson, E. 2007. Mind in Life: Biology, Phenomenology, and the Sciences of Mind. Belknap Press of Harvard University Press.

Thompson, E., and M. Stapleton. 2009. Making sense of sense-making: Reflections on enactive and extended mind theories. Topoi 28 (1): 23-30.

Thompson, E., and F. J. Varela. 2001. Radical embodiment: Neural dynamics and consciousness. Trends in Cognitive Sciences 5 (10): 418-425.

Tomasello, M. 1999. The Cultural Origins of Human Cognition. Harvard University Press.

Tomasello, M., M. Carpenter, J. Call, T. Behne, and H. Moll. 2005. Understanding and sharing intentions: The origins of cultural cognition. Behavioral and Brain Sciences 28:675-691.

Trevarthen, C. 1989. Development of early social interactions and the affective regulation of brain growth. In Neurobiology of Early Infant Behaviour, ed. C. von Euler, H. Forssberg, H. Lagercrantz, and V. Landin, 191-216. Macmillan Education UK.

Trevarthen, C., and K. J. Aitken. 2001. Infant intersubjectivity: Research, theory, and clinical applications. Journal of Child Psychology and Psychiatry, and Allied Disciplines 42 (1): 3-48.

Turvey, M. T. 1992. Affordances and prospective control: An outline of the ontology. Ecological Psychology 4 (3): 173-187.

van Gelder, T. 1998. The dynamical hypothesis in cognitive science. Behavioral and Brain Sciences 21:615-665.

Varela, F. J., E. Thompson, and E. Rosch. 1991. The Embodied Mind: Cognitive Science and Human Experience. MIT Press.

Williams, L. E., J. Y. Huang, and J. A. Bargh. 2009. The scaffolded mind: Higher mental processes are grounded in early experience of the physical world. European Journal of Social Psychology 39:1257-1267.

Zahavi, D. 2014. Self and Other: Exploring Subjectivity, Empathy, and Shame. Oxford University Press.

Zajonc, R. B. 1984. On the primacy of affect. Psychologist 39 (2): 117-123. 